NOTICE: this is the author's version of a work that was accepted for publication in Addictive Behaviors. Changes resulting from the publishing process, such as peer review, editing, corrections, structural formatting, and other quality control mechanisms may not be reflected in this document. Changes may have been made to this work since it was submitted for publication. A definitive version was subsequently published in Addictive Behaviors, Vol. 36 (2011). DOI: 10.1016/j.addbeh.2011.05.012 


\section{The Role of Executive Function in bridging the Intention-Behaviour Gap for}

\section{Binge-Drinking in University Students}

Barbara Mullan ${ }^{\mathrm{a}}$ Cara Wong ${ }^{\mathrm{b}}$, Vanessa Allom ${ }^{\mathrm{c}}$, Sophia Laurel Pack ${ }^{\mathrm{d}}$

School of Psychology, University of Sydney, Sydney, Australia

Correspondence: Barbara Mullan, University of Sydney, Sydney NSW 2006 Australia, e-mail:

${ }^{\mathrm{a} B}$ Barbara.mullan@sydney.edu.au

bcaraw@psych.usyd.edu.au, cvall2758@uni.sydney.edu.au, ${ }^{\mathrm{d}}$ spac4728@uni.sydney.edu.au 


\begin{abstract}
Background: Alcohol consumption contributes to a significant proportion of disease and the high prevalence among young adults is a worldwide health concern Purpose: To determine which aspects of executive function (EF) distinguish binge-drinkers from non binge-drinkers and to establish the role of EF in predicting behaviour. Methods: Self-report questionnaires, four tests of self-regulation and a behaviour measure were administered to 153 students. Results: The Theory of Planned Behaviour model was significant in predicting both intentions and behaviour. Although binge-drinkers and non binge-drinkers were found to differ on three of the four measures of EF, none predicted additional variance in behaviour. Planning ability and inhibition control moderated the relationship between intention and behaviour such that for individuals who intended to binge-drink, those with high planning ability or high inhibitory control were more likely to avoid doing so. Conclusions: Interventions targeting binge-drinking behaviour should aim to develop planning skills and inhibitory control.
\end{abstract}

Keywords: executive function, self-regulation, binge-drinking, theory of planned behaviour 


\section{Introduction}

Alcohol consumption contributes to a significant proportion of death, disease and injury (Pascal, Chikritzhs, \& Jones, 2009) and the high prevalence, particularly among young adults, is a worldwide concern (Moore, Smith, \& Catford, 1994; Naimi et al., 2003). Binge-drinking is characterised by the intake of an excessive amount of alcohol on a single occasion (Norman, Bennett, \& Lewis, 1998). In Australia, the National Health and Medical Research Council (NHMRC) defines binge-drinking as the consumption of four or more drinks in one session (NHMRC; 2009). Binge-drinking is especially common amongst university students (Chaloupka \& Wechsler, 1996).

The Theory of Planned Behaviour (TPB; Ajzen, 1991) has been successfully applied to the prediction of binge-drinking. Johnston and White (2003) used the TPB to predict binge-drinking behaviour and predicted $69 \%$ of variance in intention and $51 \%$ of variance in behaviour. In a meta-analysis Armitage and Conner (2001) found that the TPB accounted for 39\% of variance in intention and $27 \%$ of variance in behaviour. This difference is referred to as the 'intentionbehaviour gap'. It has been suggested that the TPB cannot completely capture the unplanned, irrational nature of health risk behaviours (Gibbons, Houlihan, \& Gerrard, 2009).

Recently, it has been speculated that executive functioning $(\mathrm{EF})$ processes may play a large role in translating intention into behaviour (Suchy, 2009). EF. Suchy (2009) proposes that EF is involved in the formation, maintenance and shifting of mental sets to develop future goals and plans, maintain the motivation and focus with which to follow through plans, and flexibly alter in 
accordance with shifting contingencies.

Studies examining EF processes and drinking behaviour have found differences between drinkers and non drinkers on measures of EF. For example, adults diagnosed with alcohol dependence have been found to have significant EF deficits when compared to a control population (Sullivan, Rosenbloom, \& Pfefferbaum, 2000). Some individuals with substance dependence have decision-making difficulties, reflecting a failure to predict negative outcomes and a tendency to seek immediate gratification (Bechara \& Damasio, 2002; Bechara, Dolan, \& Hindes, 2002). Further, Weissenborn and Duka (2003) found binge-drinkers performed poorer in spatial working memory and in pattern recognition tasks than non binge-drinkers.

Researchers examining the role of EF in predicting health behaviours have focused on the construct of self-regulation. Self-regulation, refers to the wilful regulation of internal drives in response to environmental triggers, on managing behaviour patterns (Baumeister, Schmeichel, \& Vohs, 2007). Hall and Fong (2007) have argued that avoidance of health risk requires selfregulatory abilities. In terms of avoiding binge-drinking, self-regulation may affect the implementation of intentions by inhibiting non-relevant behaviours or habitual responses such as the decision to have another drink, as well as assisting in overriding the influence of environmental triggers and by enabling the development of future plans (Palfai, 2004).

Several cognitive tasks can be utilised to measure EF, many of which have been shown to reflect elements involved in the execution of health behaviours (Allan, Johnston, \& Campbell, in press; Fadardi \& Cox, 2008). The Tower of Hanoi (TOH) reflects planning, as in order to solve the task 
efficiently time must be spent planning the moves (Wong \& Mullan, 2009). The ability to plan may be essential to avoiding binge-drinking behaviour such that having a predetermined limit on the number of drinks one is going to ingest may deter excessive consumption. The Iowa Gambling Task (IGT), (Bechara, Damasio, Damasio, \& Anderson, 1994) measures rational decision making which is necessary to judge how much to drink or when to stop drinking. Inhibition control is measured by the Stroop (MacLeod, 1991). Inhibition may be necessary to forgo the immediate gratification that alcohol provides. Finally, the Wisconsin Card Sorting Task (WCST) involves participants modifying their responses (Grant \& Berg, 1948). Altering one's behaviour once the conditions change may also be essential to avoid a binge-drinking session.

Researchers applying EF to the TPB have examined the role of self-regulation as an additional predictor of behaviour as well as a moderator of the intention-behaviour relationship (Hall, Fong, Epp, \& Elias, 2008; Wong \& Mullan, 2009). Hall et al. (2008) found that for individuals with strong EF, intention was strongly predictive of behaviours. Wong and Mullan (2009) found that planning ability predicted unique variance in breakfast consumption and moderated the association between intention and behaviour. Furthermore, Kor and Mullan (2010) found response inhibition to be the strongest predictor of sleep behaviour. Thus, the aim of the present study is to determine which particular aspects of EF may distinguish binge-drinkers from non binge-drinkers and to establish the role of EF in predicting binge-drinking behaviours.

\section{Method}

\subsection{Participants}

Participants were 153 students (113 females), with a mean age of $20.1(S D=4.2)$. 


\section{$2.2 \quad$ Procedure}

Participants completed measures of intention as well as four EF tasks. After one week participants completed a questionnaire that measured their drinking behaviour.

\subsection{Measures}

\subsubsection{Questionnaire}

Intention to engage in a binge-drinking session was calculated as the mean of three items. The three items had a Cronbach's alpha of .98.

Behaviour was measured one week later by a four item questionnaire e.g. "did you engage in a binge-drinking session over the past week", "what was greatest number of drinks consumed in a session?".

\subsubsection{Executive Function Measures}

The Tower of Hanoi (Welsh \& Huizinga, 2001) requires that an initial start configuration of disks be transformed into a specific goal state in the minimum number of moves. Longer time spent preplanning indicates superior planning ability.

The Stroop Task (Stroop, 1935) compared the time taken to name the ink colour of a colour word printed in an incongruent colour (e.g. naming the colour red when the word "blue" is printed in red ink) with the time taken to name the colour with neutral stimuli. A smaller difference score 
indicated superior inhibition of responses.

In The Iowa Gambling Task (Bechara, Damasio, Tranel, \& Damasio, 2005) participants were required to place bets on one of four decks of cards which each resulted in different degrees of loss or gain. The task consisted of 50 trials. A greater amount of money remaining at the end of the task indicated that participants were more rational in their decision making.

In The Wisconsin Card Sorting Task (Berg, 1948) participants are provided with the response deck and were required to match each card from the response deck to the stimulus card which they feel is the correct category. Once the participant has worked out the rule the property by which the cards are to be sorted changes and the participant must work out the new rule. Fewer number of errors indicated superior cognitive flexibility.

\section{Results}

Twenty-sex percent $(n=40)$ reported engaging in binge-drinking. The average number of drinks consumed in one session was $6.5(S D=3.23)$ and the average number of binge-drinking sessions in one week was $1.20(S D=.65)$. Based on the number of drinks consumed $19 \%(n=29)$ were binge-drinkers ( 5 or more drinks), 33\% ( $n=50)$ were moderate drinkers (no more than 5 drinks) and $48 \%(n=74)$ were classed as non drinkers.

\subsection{TPB and EF}

Intention predicted $37.6 \%$ of the variance in behaviour (see Table I). None of the four measures of EF significantly predicted any additional variance $\left(F_{4,147}=.56, p=.69\right)$. Intention and the four EF variables were mean centred and product interactions were computed and added 
consecutively to explore if EF measures could moderate the intention-behaviour relationship. Both planning, measured by the $\mathrm{TOH},\left(F_{1,146}=4.70, p=.03\right)$ and inhibition, measured by the Stroop task $\left(F_{1,145}=4.76, p=.03\right)$ were found to moderate the relationship between intention and behaviour. The interaction effects of intention and planning, and response inhibition added an additional $6 \%$ of the variance explained in behaviour.

\subsection{EF Measures}

One-way ANOVAs revealed that binge-drinkers $(M=1.46, S D=.68)$ performed significantly poorer on the IGT than non binge-drinkers $\left(M=1.72, S D=.60 ; F_{(1,151)}=5.17, p=.02\right)$. Oneway ANOVAs showed significant differences between binge-drinkers, moderate drinkers and non drinkers for the Stroop task and the TOH. Post-hoc Tukey tests showed that moderate drinkers were significantly better than non drinkers in the Stroop task $(p<0.01)$. Further, moderate drinkers were significantly better than binge-drinkers in the $\mathrm{TOH}(p=.04)$.

\section{Discussion}

Intention was moderately predictive (37\%) of binge-drinking behaviour but EF tasks did not account for additional variance. This is dissimilar to previous research, for example, Allan, Johnson and Campbell (2010) found that inhibition scores explained additional variance in unintentional eating, while Wong and Mullan (2009) found that planning scores accounted for additional variance in breakfast consumption. Nonetheless, despite these tasks failing to predict unique variance in behaviour, binge-drinkers could be distinguished from non binge-drinkers using scores from the tasks. The IGT revealed significant differences between the two groups such that binge-drinkers performed significantly poorer, indicating that binge-drinkers had a 
tendency to make riskier decisions. Interventions that teach rational decision-making strategies may be useful for reducing alcohol consumption in binge-drinkers.

Moderate drinkers had greater inhibitory control than non-drinkers. This implies that avoiding a binge-drinking session; that is stopping at four drinks, requires greater inhibitory control. Baumeister et al. (2007) suggest that self-regulation can be strengthened with practice, thus the superior inhibitory control exhibited by moderate drinkers may be the result of constant restraint. Binge-drinkers and moderate drinkers differed on $\mathrm{TOH}$ scores, such that moderate drinkers spent more time planning than binge-drinkers, suggesting that planning ability is useful in avoiding binge-drinking. Having a pre-determined number of drinks that one intends to consume increases the probability that intentions to not binge-drink are achieved by connecting the intended action to a situational cue, for example: the fourth drink, which once encountered elicits the behaviour; cease drinking, without the need for extensive deliberation (Gollwitzer, 1999).

Inhibition and planning affected intention-behaviour translation. Within individuals who intended to binge-drink, those with higher planning ability drank less than those with lower planning ability. This is consistent with Wong and Mullan (2009) who found planning to moderate the intention-behaviour gap for breakfast consumption, however, it was found that those with low intentions were influences by planning ability rather than those with high intentions. This may be due to the nature of the behaviours: breakfast consumption is a healthprotective behaviour while binge-drinking is a health-risk behaviour. Self-regulation may be needed to counteract intentions which are detrimental, that is, not intending to eat breakfast but intending to engage in binge-drinking behaviour. 
Within individuals who intended to binge-drink, those who exhibited greater inhibitory control were less likely to engage in a binge-drinking session than those with lower inhibitory control. This finding is consistent with Hall et al. (2008) who also found inhibition to differentially effect the implementation of dietary and exercise behaviour at high levels of intention. Further, previous studies examining inhibitory control, but using addiction related stimuli in the Stroop task, found that addicted individuals exhibited cognitive biases towards addiction stimuli which were difficult to inhibit and that the effort required to do so detracted from intentional cognitive activity (McCusker, 2001). Accordingly, future interventions need to target those with poor inhibitory control.

There are a number of limitations to consider. The sample consisted of young Australian adults so the generalisability of these results to other groups may be questionable. Further, self-report questionnaires were used which may have lead to recall biases. Despite these limitations, the current study demonstrated that individual differences in EF moderated the relationship between intention and behaviour such those with high intentions to binge-drink and high planning ability or inhibitory control were less likely to engage in a binge-drinking session. Further, scores on planning, inhibitory control and risky decision-making tasks differentiated between bingedrinkers and moderate drinkers and non drinkers. These results could be usefully applied to interventions aimed at reducing binge-drinker behaviour.

\section{References}

Ajzen, I. (1991). The Theory of Planned Behaviour. Organizational Behavior and Human Decision Processes, 50, 179-211. 
Ajzen, I. (2002). Constructing a TPB questionnaire: Conceptual and methodological considerations. http://people.umass.edu.ajzen/pdf/tpb.measurement.pdf Retrieved 23rd March 2010

Allan, J., Johnston, M., \& Campbell, N. (2010). Unintentional eating. What determines goalincongruent chocolate consumption? Appetite, 54(2), 422-425.

Allan, J., Johnston, M., \& Campbell, N. (in press). Missed by an inch or a mile? Predicting size of intention-behaviour gap from measures of executive control. Psychology \& Health.

Armitage, C., \& Conner, M. (2001). Efficacy of the theory of planned behaviour: a meta-analytic review. British Journal of Social Psychology, 40(4), 471-499.

Australian Institute of Health and Welfare. (2008). 2007 National Drug Strategy Household Survey: First Results. Retrieved September 15, 2010, from http://www.aihw.gov.au/publications/phe/ndshs07-fr/ndshs07-fr-no-questionnaire.pdf

Baumeister, R. F., Schmeichel, B. J., \& Vohs, K. D. (2007). Self-regulation and the executive function: The self as controlling agent. In Social psychology: Handbook of basic principles (pp. 516-539).

Bechara, A., Damasio, A., Damasio, H., \& Anderson, S. (1994). Insensitivity to future consequences following damage to human prefrontal cortex. Cognition, 50, 7-15.

Bechara, A., \& Damasio, H. (2002). Decision-making and addiction (part I): impaired activation of somatic states in substance dependent individuals when pondering decisions with negative future consequences. Neuropsychologia, 40(10), 1675-1689.

Bechara, A., Damasio, H., Tranel, D., \& Damasio, A. R. (2005). The Iowa Gambling Task and the somatic marker hypothesis: some questions and answers. Trends in Cognitive Sciences, 9(4), 159-162. 
Bechara, A., Dolan, S., \& Hindes, A. (2002). Decision-making and addiction (part II): myopia for the future or hypersensitivity to reward? Neuropsychologia, 40(10), 1690-1705.

Berg, E. A. (1948). A simple objective test for measuring flexibility in thinking. Journal of General Psychology, 39, 15-22.

Chaloupka, F. J., \& Wechsler, H. (1996). Binge drinking in college: The impact of price, availability, and alcohol control policies. Contemporary Economic Policy, 14(4), 112124.

Conner, M., Norman, P., \& Bell, R. (2002). The Theory of Planned Behavior and Healthy Eating. Health Psychology 21(2), 194-201.

Cooke, R., Sniehotta, F., \& Schuz, B. (2007). Predicting Binge-Drinking Behaviour Using an Extended TPB: Examining the Impact of Anticipated Regret and Descriptive Norms. Alcohol and Alcoholism, 42(2), 84.

Fadardi, J. S., \& Cox, W. M. (2008). Alcohol-attentional bias and motivational structure as independent predictors of social drinkers' alcohol consumption. Drug and Alcohol Dependence, 97(3), 247-256.

Fishbein, M., \& Ajzen, I. (1975). Belief, attitude, intention, and behaviour: An introduction to theory and research. Reading, M.A: Addison-Wesley.

Gibbons, F. X., Houlihan, A. E., \& Gerrard, M. (2009). Reason and reaction: The utility of a dual-focus, dual-processing perspective on promotion and prevention of adolescent health risk behaviour. British Journal of Health Psychology, 14(2), 231-248.

Godin, G., \& Kok, G. (1996). The Theory of Planned Behavior: A Review of Its Applications to Health-Related Behaviors. American Journal of Health Promotion, 11(2), 87-98.

Gollwitzer, P. M. (1999). Implementation intentions: Strong effects of simple plans. American 
Psychologist, 54(7), 493-503.

Grant, D., \& Berg, E. (1948). A behavioral analysis of degree of reinforcement and ease of shifting to new responses in a Weigl-type card-sorting problem. Journal of Experimental Psychology, 38(4), 404-411.

Hall, P., Fong, G., Epp, L., \& Elias, L. (2008). Executive function moderates the intentionbehavior link for physical activity and dietary behavior. Psychology \& Health, 23(3), 309-326.

Hall, P. A., \& Fong, G. T. (2007). Temporal self-regulation theory: A model for individual health behavior. Health Psychology Review, 1(1), 6-52.

Johnston, K., \& White, K. (2003). Binge-drinking: A test of the role of group norms in the theory of planned behaviour. Psychology \& Health, 18(1), 63-77.

Kor, K., \& Mullan, B. (2010). Sleep Hygiene Behaviours: An application of the theory of planned behaviour and the investigation of perceived autonomy support, past behaviour and response inhibition. Submitted 9th Feb 2010.

MacLeod, C. M. (1991). Half a century of research on the Stroop effect: An integrative review. Psychological Bulletin, 109(2), 163-203.

McCusker, C. (2001). Cognitive biases and addiction: an evolution in theory and method. Addiction, 96(1), 47-56.

Moore, L., Smith, C., \& Catford, J. (1994). Binge drinking: prevalence, patterns and policy. Health Education Research, 9(4), 497.

Naimi, T. S., Brewer, R. D., Mokdad, A., Denny, C., Serdula, M. K., \& Marks, J. S. (2003). Binge drinking among US adults. JAMA, 289(1), 70.

National Health and Medical Research Council. (2009). Australian guidelines to reduce health risks 
$\begin{array}{llll}\text { from drinking } & \text { alcohol } & \text { [Electronic } & \text { Version], }\end{array}$ http://www.nhmrc.gov.au/your_health/healthy/alcohol/index.htm

Norman, P., Bennett, P., \& Lewis, H. (1998). Understanding binge drinking among young people: An application of the theory of planned behaviour. Health Education Research, 13(2), 163.

Norman, P., \& Conner, M. (2006). The theory of planned behaviour and binge drinking: Assessing the moderating role of past behaviour within the theory of planned behaviour. British Journal of Health Psychology, 11(1), 55-70.

Palfai, T. (2004). Automatic processes in self-regulation: Implications for alcohol interventions. Cognitive and Behavioral Practice, 11(2), 190-201.

Pascal, R., Chikritzhs, T., \& Jones, P. (2009). Trends in estimated alcohol-attributable deaths and hospitalisations in Australia, 1996-2005. National Alcohol Indicators, Bulletin, 12.

Saitz, R., Palfai, T., Freedner, N., Winter, M., Macdonald, A., Lu, J., et al. (2007). Screening and brief intervention online for college students: the ihealth study. Alcohol and Alcoholism, $42(1), 28$.

Stein, K. D., Goldman, M. S., \& Del Boca, F. K. (2000). The influence of alcohol expectancy priming and mood manipulation on subsequent alcohol consumption. Journal of Abnormal Psychology, 109(1), 106.

Stroop, J. R. (1935). Studies of interference in serial verbal reactions. Journal of Experimental Psychology: General, 18, 643-662.

Suchy, Y. (2009). Executive functioning: Overview, assessment, and research issues for nonneuropsychologists. Annals of Behavioral Medicine, 37(2), 106-116.

Sullivan, E., Rosenbloom, M., \& Pfefferbaum, A. (2000). Pattern of motor and cognitive deficits in detoxified alcoholic men. Alcoholism: clinical and experimental research, 24(5), 611- 
621.

Todd, J. (2011, 9-11th Feb). Using the Theory of Planned Behaviour and Prototype Willingness Model to Target Binge Drinking in Undergraduate University Students. Paper presented at the The Australasian Society of Behavioural Health and Medicine (ASBHM) 8th Annual Scientific Conference, Auckland, New Zealand.

Weissenborn, R., \& Duka, T. (2003). Acute alcohol effects on cognitive function in social drinkers: their relationship to drinking habits. Psychopharmacology, 165(3), 306-312.

Welsh, M. C., \& Huizinga, M. (2001). The development and preliminary validation of the Tower of Hanoi-Revised. Assessment, 8, 167-176.

Willcutt, E., Doyle, A., Nigg, J., Faraone, S., \& Pennington, B. (2005). Validity of the executive function theory of attention-deficit/hyperactivity disorder: a meta-analytic review. Biological Psychiatry, 57(11), 1336-1346.

Wong, C., \& Mullan, B. (2009). Predicting Breakfast Consumption: An application of the Theory of Planned Behaviour and the Investigation of Past Behaviour and Executive Function. British Journal of Health Psychology, 14(3), 489-504. 
Table I

Final Step of Hierarchical Regression Analysis: Planning, Inhibition, Decision Making and Cognitive Flexibility as Predictors of Behaviour and Moderators of Intention and Behaviour

\begin{tabular}{|c|c|c|c|c|c|c|}
\hline Model & Variable & $\beta$ & $t$ & $R^{2}$ & $\Delta R^{2}$ & $p$ \\
\hline Step 1 & INT & .613 & 9.531 & .376 & & $<.001 *$ \\
\hline \multirow[t]{10}{*}{ Step 2} & INT & .621 & 9.709 & & & $<.001 * *$ \\
\hline & TOH & -.082 & -1.292 & & & .199 \\
\hline & STP & -.013 & -.198 & & & .843 \\
\hline & IGT & -.024 & -.367 & & & .714 \\
\hline & WCST & -.009 & -.138 & & & .890 \\
\hline & INTxTOH & -.139 & -2.189 & & & $.030 *$ \\
\hline & INTxSTP & .135 & 2.128 & & & $.035^{*}$ \\
\hline & INTxIGT & -.066 & -1.034 & & & .303 \\
\hline & INTxWCST & .061 & .962 & & & .338 \\
\hline & & & & .431 & .004 & .338 \\
\hline
\end{tabular}

Note. Dependent variable $=$ binge-drinking behaviour (drinks per session), INTxTOH = product interaction of intention and planning ability, INTxSTP = product interaction of intention and inhibition, INTxIGT = product interaction of intention and decision making, INTxWCST = product interaction of intention and cognitive flexibility, overall $R^{2}=.431$, ** denotes statistical significance at the .01 level, * denotes statistical significance at the .05 level 
Table II

Differences in EF Scores Based on Number of Drinks Consumed in a Session

\begin{tabular}{lllllll}
\hline & Binge-Drinker & Moderate Drinker & Non Drinker & & & \\
& \multicolumn{1}{c}{ Task } & $\boldsymbol{M}$ & $\boldsymbol{M}$ & $\boldsymbol{d}$ & $\boldsymbol{F}$ & $\boldsymbol{p}$ \\
\hline TOH & $13.76_{\mathrm{a}}$ & $24.27_{\mathrm{b}}$ & $18.06_{\mathrm{ab}}$ & 150 & 3.43 & $.035^{*}$ \\
STP & $223.81_{\mathrm{ab}}$ & $101.74_{\mathrm{a}}$ & $300.33_{\mathrm{b}}$ & 150 & 5.31 & $.006^{* *}$ \\
IGT & 1.49 & 1.76 & 1.64 & & & \\
WCST & 47.04 & 47.88 & 44.64 & 150 & 1.80 & .169 \\
\end{tabular}

Note. Means with the same subscript do not differ significantly at the .05 level according to the Tukey HSD test 